\title{
Intervenciones desde la ligereza. Notas sobre escritura y política en Osdany Morales y Jorge Enrique Lage
}

\section{Lightness interventions: notes on writing and politics in Osdany Morales y Jorge Enrique Lage}

\author{
Laura Maccioni \\ maccionilau@gmail.com \\ Centro de investigaciones y estudios sobre cultura \\ y sociedad. CONICET y Universidad Nacional de \\ Córdoba, Argentina
}

Recepción: 27 Abril 2020

Aprobación: 25 Agosto 2020

Publicación: 06 Noviembre 2020

Cita sugerida: Maccioni, L. (2020). Intervenciones desde la ligereza. Notas sobre escritura y política en Osdany Morales y Jorge Enrique Lage. Orbis Tertius, 25(30), e165. https://doi.org/10.24215/18517811e165

\begin{abstract}
Resumen: Se analizan un conjunto de textos de Osdany Morales y Jorge Enrique Lage recuperando el gesto político de una escritura que se ha liberado de la carga de representar cualquier fundamento previo. Lejos de referir a alguna verdad profunda, se propone que este gesto ocurre a nivel de la superficie de la escritura misma: como indagación acerca del acto de escribir y como afirmación de lo que puede la escritura, más allá de las específicas condiciones de producción en Cuba.
\end{abstract}

Palabras clave: Literatura cubana, Política, Osdany Morales, Jorge Enrique Lage.

\begin{abstract}
A corpus of texts by Osdany Morales and Jorge Enrique Lage is analyzed, recovering the political gesture of a writing that has been freed from the burden of representing any previous foundation. Far from referring to any profound truth, it is proposed that this political gesture occurs at the surface level of writing itself: as an inquiry on the act of writing, and as an affirmation of what writing can do, beyond the unfavorable production conditions in Cuba.
\end{abstract}

Keywords: Cuban literature, Politics, Osdany Morales, Jorge Enrique Lage.

\section{INTRODUCCIÓN}

Dice Carlos A. Aguilera en su prólogo a Teoría de la transficción. Narrativa(s) cubana(s) del siglo XXI que "nada se escucha tanto en el espacio literario como el término ligereza": ya sea que se lo invoque como elogio o como defecto, hay un consenso general en que la ligereza "es una de las marcas de la narrativa o arte del siglo XXI" (Aguilera, 2020). En el caso específico de la literatura cubana, el autor de El imperio Oblomov detecta esta marca no sólo en la obra de los escritores que publican en los años previos al cambio de siglo, sino también en la de los llamados Generación cero, rótulo que, no sin polémicas y cuestionamientos (Puñales Alpízar, 2018; Dorta, 2017; Mora y Pérez, 2017; Grillo y Luis, 2008), agrupa a un conjunto de jóvenes que publican por primera vez después del año 2000 o año cero. La "ligereza" de los textos de estos últimos no sólo ha sido advertida por Aguilera: otros críticos también han recurrido a nociones similares para describir su producción, señalando en ella su "ingravidez" (Cisneros Casamayor, 2013) o su carácter "flotante" (Rojas, 2018). En cualquier caso, la observación de Aguilera se completa con una aclaración: si la noción de ligereza parece sugerir que cuando hablamos de estos escritores estamos en presencia de una literatura en la que 
predomina la "no profundidad, no reflexión, poco desarrollo", en verdad lo que ocurre aquí "es exactamente lo opuesto". La ligereza — advierte - " $[\mathrm{P}]$ udiera definirse como lo que ya no necesita mostrarse desde la psicología u ontología — una relación familiar por ejemplo- para despiezarse y ser asimilada de manera "abyecta”, es decir, sin ningún tipo de justificación, de código" (Aguilera, 2020)

En este ensayo me interesa ofrecer algunos argumentos que surgen de la lectura de un corpus de textos de dos autores cuyos nombres suelen incluirse entre los integrantes de la Generación cero -Osdany Morales (1981) y Jorge Enrique Lage (1979) - con el objetivo de profundizar en la reflexión de Aguilera recién citada, puesto que, entiendo, en esa reflexión queda tendida una invitación a pensar las relaciones entre lo ligero y lo político. O más bien, si seguimos su línea de razonamiento, a pensar la condición política de la ligereza en tanto operación de des-conocimiento de códigos y ruptura de ordenamientos que pudieran servir como fundamento o justificación de un supuesto vínculo natural entre literatura y representación de verdades o identidades últimas.

En este sentido, propongo que la ligereza de los textos que voy a examinar quedaría en evidencia en el hecho de que se han descargado del peso de representar la historia o de la misión de recuperar la pureza del origen. Asimismo, digo que su proclamada falta de profundidad no tiene tanto que ver con su falta de referencia o de penetración en alguna verdad entrañable, sino con que todo lo que necesitan decir ocurre a nivel de la superficie de la escritura misma: en estos textos, escribir es, a un mismo tiempo, escribir acerca de la escritura y acerca de la eficacia de ésta en el mundo, más allá de lo hostil que puedan ser sus condiciones de producción, especialmente en la isla. Dicho de otro modo, escribir tiene que ver con una indagación acerca de qué cosa se hace cuando se escribe, pero, además, con dar cuenta del problema de escribir en/desde Cuba. La huella de Lorenzo García Vega, por mencionar algunos nombres, es reconocible en la primera cuestión; la fe irrevocable que los textos de Reinaldo Arenas profesan en lo que la escritura puede resuena en la segunda.

Leeré, entonces, un conjunto de textos de Osdany Morales y de Jorge Enrique Lage a la luz de estas claves que considero permitirían entender el tipo de intervención política que se juega en sus escrituras; esto es, poniendo en evidencia lo que ellas tienen de polémicas aún cuando "inadviertan" (Padilla Cárdenas, 2014, p.119) o escapen de los lugares hacia los cuales reconduce insistentemente la institución literaria de la isla en su afán de salvaguardar los tópicos que amarran la cultura nacional a un proyecto estatal. Y sin embargo, digo, la resistencia a la fuerza de atracción ideológica de esos bloques de sentido no se da por la oposición de una fuerza de valor contrario; estos textos no se inscriben en la lógica del antagonismo, sino que recurren a ciertas estrategias de escape de esos escenarios y de afirmación del poder inmanente de la literatura que analizaré a continuación.

\section{OSDANy Morales: LA ESCRITURA COMO DESANCLAJE}

La novela Papyrus (2012), de Osdany Morales, reúne textos producidos en distintos contextos y publicados en distintos soportes: - un texto leído en Casa de las Américas, otros publicados en revistas virtuales, otros en revistas publicadas en papel - apenas hilvanados a partir de una historia mínima: un escritor emprende un viaje por las Siete Bibliotecas del mundo, pero la condición para entrar en cada una de ellas es que debe dejar un libro escrito. Lo que leemos es la historia de ese viaje y de los libros que a lo largo del recorrido el narrador va escribiendo. Relatos dentro de relatos, Papyrus lleva la acción de narrar a un grado de inflación tal que casi no queda nada por comunicar más que el hecho de narrar mismo. Podríamos entonces leer la novela Papyrus como una apuesta por la proliferación de signos, como producción excesiva de palabras que borra la memoria de cualquier discurso fundador. De allí que en las peripecias que relatan los siete libros se repita siempre, como un mantra, las mismas dos frases: Todo se va, pero también queda, es una de ellas. La otra: El centro es inmóvil, pero minúsculo. La primera parecería acometer contra la Historia, contra la idea del tiempo como sucesión lineal y continua, sugiriendo en cambio la imposibilidad de los finales y los comienzos. La segunda parecería tener un sentido semejante, pero aplicado al territorio del Lenguaje, o tal vez del Archivo: si admite la existencia de un núcleo que permanece inmóvil ante la contingencia, reconoce al mismo tiempo la debilidad de su fuerza gravitacional; concede la existencia de un 
(micro)centro, pero lo rebaja en su capacidad de, por así decirlo, irradiación, determinación u organización de lo que está a su alrededor.

Una multiplicidad de lugares, de tiempos y de materiales de archivos de la cultura global se superponen y acoplan a lo largo de Papyrus, desdibujando cartografías y cronologías. El resultado es la compilación de un flujo incesante de hablas y relatos que se dilata y se expande al punto tal de que queda liquidada la posibilidad de identificar algún nudo o sustrato narrativo, un mensaje del cual un narrador estable sea el portador, una memoria cultural que restituya el pasado. Papyrus nos entrega una sucesión de historias que brotan de otras historias, microrrelatos encapsulados que se vinculan entre sí por acumulación. Frente a ciertas lecturas que han creído ver en este texto de Osdany Morales un homenaje a las bibliotecas (Villasana, 2013; Navia, 2013) y al valor totémico del archivo que ellas guardan — de hecho la traducción al inglés del título fue The last librarian - o bien un acto reverencial hacia el narrador como aquél que domina el arte de hacer relatos con otros relatos contribuyendo así al engrosamiento del patrimonio escriturístico de alguna entidad trascendente, yo leo en Papyrus un esfuerzo por vincular el relato con la idea de pérdida, de desposesión de certezas que es inherente al acto de representar. Narrar, añadir un relato o un libro más a la masa de discursos existentes es llevar a cabo un acto político que consiste en alimentar la incertidumbre, habilitar la posibilidad del olvido, impedir que los discursos anclen en algún punto fijo y definitivo. No resulta casual que en la visita a la primera biblioteca la conversación con el bibliotecario recuerde el cuento "El libro de arena", y en particular al ancla dibujada como por una mano infantil, que el narrador del cuento de Jorge Luis Borges ve la primera vez que abre el libro, pero que no podrá reencontrar nunca más. Sin embargo, a diferencia del bibliotecario borgiano que compra ese diabólico objeto y luego lo esconde en la Biblioteca Nacional para escapar del horror que le provoca un libro que se escribe a medida que se lo lee, en Papyrus hay una aceptación casi gozosa de esa inestabilidad significante, de esa imposibilidad de establecer jerarquías y líneas de sentido, de esa fragmentariedad que no se resuelve en ninguna figura totalizadora.

Narrar, en síntesis, como modo de impedir la coagulación del Sentido, como aplicación del método de lo que uno de los personajes llama "ficción automática": narrar maquínicamente, hacer una literatura que sea el equivalente a las máquinas de Picabia en la pintura (Morales, 2012, p. 22), desfondar el yo como soporte de alguna seguridad. Hacer de la sede autoral el lugar del robo y el invento, pero reconociendo, al mismo tiempo, que no se podría hacer nada diferente a eso: no podría reponerse ninguna verdad aun cuando el autor quisiera hacerlo. De esto mismo habla Morales en su cuento, "Las playas albinas", singular homenaje a Lorenzo García Vega en clave de policial. Publicado por primera vez en 2011 en la revista Quimera, el relato se inicia con un motivo que aparece reiteradamente en la literatura cubana del siglo XXI: el tráfico de libros a través de archivos digitales, el acceso fragmentario y de segunda mano a la literatura contemporánea. En el comienzo del texto el narrador nos informa que ha recibido en un pdf las primeras 48 páginas del libro de memorias de Lorenzo García Vega que lleva por título El oficio de perder. "Desde hacía un tiempo tenía gran interés por leer estas páginas. Porque hasta entonces no había leído a Lorenzo García Vega. O al menos no había estado tan cerca de uno de sus libros, y las fotocopias - no fueron hechas por mí, yo solo las recibí en un pdf y las imprimí- son lo más cercano que he estado de su obra" (Morales, 2014, p.13), nos dice. Pero, como ocurre en los policiales, esas páginas escritas presentan un enigma para el lector, que no sólo aspira a conocer a García Vega a través de un fragmento de sus memorias, sino que además aspira a completar la información que falta en ese fragmento para reconstruir su sentido:

En mi primera aproximación descubrí que en sus memorias invocaba a personajes, tal vez célebres, que al mismo tiempo me resultaban desconocidos. Personajes que no se presentan en el texto y que son traídos familiarmente por el autor, como si el lector tuviera la obligación de conocerlos de antemano. Decidí avanzar por los nombres que de un modo u otro la vida de lector que yo había vivido hasta entonces me había escamoteado. Conté un total de siete, para mí, desconocidos, mencionados con nombre y apellido [...]: Hortensia Gronlier, Enrique Fierro, Ida Vitale, Elisa Lerner, Agustín Acosta, Juan Liscano y Dardo Cúneo. Estos son los archivos de mi acomodada investigación, para la cual conté con una laptop conectada a Internet, un cuaderno de apuntes, un teléfono, los papeles impresos por ambos lados. (2014, p.13) 
Con este tono detectivesco, el narrador nos hace cómplices de una pesquisa obsesiva a través de la web, de llamados por teléfono a otros países, de búsquedas en bibliotecas con el objetivo de completar un relato en el que faltan piezas. Su investigación arroja resultados incompletos, parciales, descontextualizados: a veces consigue datos biográficos de alguno de estos personajes, otras su foto, su firma, su obituario, incluso los datos del homónimo de uno de los mencionados en el libro a quien termina invitando como amigo en facebook. Pero aquí también aparece la incertidumbre como un elemento fundamental del archivo. En sus memorias, García Vega habla de una fiesta de fin de año, en una casa cerca de Caracas, a la que acude con el escritor venezolano Juan Liscano y el intelectual argentino Dardo Cúneo. Corre el alcohol, hay mucha gente, las imágenes están desdibujadas. De esa fiesta García Vega recuerda el momento en que Cúneo le comenta que sus memorias se habrían de llamar El oficio de perder, y que un rato más tarde, mientras está orinando en el baño de la mansión de Caracas, decide robarle el título para ponérselo a las suyas. Pero ocurre algo más: tratando de recordar otro detalle de esa misma noche, García Vega escribe: "A lo mejor, si se lo preguntamos a Liscano, este tampoco lo sabe. Y en cuanto a Dardo, ¡ay!, ya no se le puede preguntar. Dardo se murió” (2014, p.34). Y es aquí donde el narrador de "Las playas albinas" hace un descubrimiento: "en nuestros apuntes tenemos lo siguiente: en ese entonces —el entonces del año de la publicación [de El oficio de perder], 2004 - Juan Liscano ¡ay!, había muerto, y Dardo aún vivía. ¿Habría estado Lorenzo haciendo bromas sobre la muerte de sus amigos?" (2014, p.34) duda el narrador. Y continúa razonando: "La opción más posible, pero insólita, es que los haya intercambiado en su memoria, y por momentos de la fiesta final donde dice Juan debe leerse Dardo." De ser así, concluye, Liscano no solo habría sido desterrado de su propiedad intelectual, sino de la posibilidad de, al menos, "una justicia poética": sea debido a la confusión de una noche regada por el alcohol, sea por su vejez, García Vega muestra una sola jugada cuando en verdad habría realizado dos. El hallazgo desconcierta al narrador-detective: “¿qué hago yo ahora con este descubrimiento?” se pregunta. Y sigue: "Con todos mis personajes desconocidos me he equivocado, o se han equivocado ellos. Han estado a tiempo para algo, pero son muy viejos para enmendar nada. Rozan la impunidad. Lo que entendemos por el tiempo es ese error" (2014, p.36). Si fue una pulsión documental la que llevó al narrador a investigar en el archivo Lorenzo García Vega, esa pulsión quedará insatisfecha, pues lo que encuentra sólo aporta incerteza, ambigüedad. Convencido de que el buen lector es el que se impone el deber de saber lo mismo que el autor como garantía de sentido último ("como si el lector tuviera la obligación de conocerlos [a las personas que nombra García Vega] de antemano” (p.13), había dicho al principio), el narrador emprende una investigación de la que espera obtener los datos que le faltan; pero su investigación termina mostrando que, al igual que él, el autor tampoco sabe y que, peor aún, la autoridad de su testimonio se ha diluido en la impunidad de robos voluntarios y olvidos involuntarios. También aquí queda impedido o deflacionado cualquier intento de constatación identitaria: mientras el narrador escribe los resultados de su pesquisa casi como notas al pie del texto de Lorenzo García Vega, saturando de glosas lo que cuentan esas 48 páginas de sus memorias, éstas, lejos de volverse más precisas, se van revelando en su carácter indecidible, ficcional, irrecuperable para cualquier gesto que aspire a hacer de ellas un documento de algo o que busque en ella una autobiografía. En síntesis, aquí tampoco el archivo aporta evidencia testimonial de ninguna verdad, ni tampoco puede ser invocado desde ningún paradigma representacional. El centro es inmóvil, pero minúsculo: apenas un nombre - Lorenzo García Vega - que sirve para abarrotar una masa de enunciados autistas, cuando no ajenos, que se van acumulando sin orden alguno como quien carga mercaderías en el carrito del supermercado.

Este desanclaje, digo, esta salida de cauce de la escritura por la vía del exceso es la estrategia de Osdany Morales para escapar de cualquier texto tutor: sea porque abre el grifo de la narración para que fluyan relatos en un torrente que arrasa con cualquier sentido; sea porque, en la estela de la escritura del propio Lorenzo García Vega, los enunciados terminan acumulándose abigarradamente en un no-relato. Esto es, se propone escribir algo sobre algo, pero no logra su cometido porque el objeto que el discurso quiere capturar es vago, equívoco y por tanto nada concreto puede decir de él, dando por resultado un relato que narra el fracaso de relatar. En cualquier caso, los textos de Morales resisten a una lectura que apunte al consabido anclaje de éstos 
en el archivo de las ficciones sobre la nación: una búsqueda tal pronto constataría que esta huida de los límites de lo decible, este trabajo de in-utilización del lenguaje al que nos referíamos — sea a través del desborde de la narración, sea a través de la declaración de su ineficacia como vía de acceso a alguna verdad- más bien estaría dando cuenta de una desistencia o renuncia a reconocer - afirmándolas u oponiéndose a ellas - las reglas de un campo literario nacional cuya lógica político-institucional ha apuntado desde hace décadas a encauzar y territorializar los proyectos literarios de los escritores cubanos, a gestionar sus usos de la lengua, a premiar ciertos géneros y estilos, a configurar identidades cívicas, en fin, a asegurar su funcionalización política.

\section{ESCRIBIR EN /DESDE CUBA: LO QUE PUEDE LA LITERATURA}

La posición de Morales frente a esta última cuestión aparece esbozada en "Querido sobrino Gobo" (2011), una especie de ensayo-ficción que reflexiona acerca de las condiciones que fijan a su escritura las políticas culturales estatales, pero también las políticas de las casas editoriales internacionales, en un contexto en el que, desde comienzos del siglo XXI, el modelo económico cubano experimenta gradualmente un proceso de apertura al mundo. En este relato desopilante, un escritor de nombre Os (Osdany) entrevista al cantante Juan Luis Guerra, apasionado coleccionista de la nueva narrativa cubana. El título alude a la serie para niños Fraggle Rock, cuyos protagonistas, los fraggles, son unos muñecos que viven en algo así como cuevas aisladas. Uno de ellos, Matt el viajero, es el único fraggle que ha salido al mundo exterior, y desde allí le envía cartas que narran sus increíbles aventuras por fuera de la cueva a su sobrino Gobo, cartas que comienzan siempre con el encabezado que Morales usa como título. Como el sobrino Gobo que conoce el mundo a través del tío Matt, Os termina de entender lo que sucede en el campo de la literatura cubana contemporánea cuando se lo explica el dominicano compositor de bachatas, esto es, alguien que lo mira desde afuera y desde lo que vendrá. Y, al igual que en Papyrus y en "Las playas albinas", tampoco en este caso será posible anclarse en algún territorio firme, pues, por el contrario, a lo largo de la entrevista el autor de Galá que llueva café deja en claro su rechazo tanto por la literatura que se escribe para satisfacer las exigencias de las políticas culturales oficiales, pero también por la literatura que consagran los grandes grupos editoriales internacionales. En otras palabras, lo que ocurre es que son las políticas editoriales las que terminan decidiendo qué libros escribe el escritor. Con respecto al funcionamiento del campo literario cubano y su escasa autonomía con respecto al Estado, dice:

[...] la principal postura a la hora de sentarme cómodamente a leer a un nuevo autor cubano es el hecho de interpretar que su libro pudo haber sido otro, muy distinto, y que lo que tenemos a mano a veces no es más que unas pocas indicaciones para llegar al original. Me gusta [...] recrear los encuentros, reales o imaginarios, con alguna manifestación de censura. Actualizar el libro que hubiera sido o aquel que el autor hubiera escrito en otras condiciones. Y me pregunto constantemente si la apropiación de determinados géneros, la elección de ciertos patrones en la literatura cubana contemporánea no son el resultado de esa fuga premeditada del pabellón de lo inédito hacia las anchas y ventiladas praderas de la publicación nacional.

[...] lo más interesante al hablar de literatura cubana de los últimos años es que la isla supone un aislamiento que no alcanza sólo a los nuevos autores desorientados, sino también a esas hordas de legitimación ya crecidas dentro del aislante; verbigracia críticos, editores, jurados... Muchas de las propuestas de estos escritores consiguen cierta visibilidad, incluso la publicación, por el hecho de ganar un premio literario, ya sea con un relato o con un volumen terminado [...] Esto hace que lo que más se muestre de la nueva literatura sea el producto de la lectura de un jurado, que no siempre está actualizado o comprometido [...] en Cuba se escribe literatura como si en la bolita del mundo se hubiera dejado de escribir. Es sorprendente [...] encontrar una página que haya sido redactada bajo el influjo más genuino de la creación. (Morales, 2011, p.50-51)

Pero si el medio aislante ha fructificado en "hordas de legitimación" que determinan "la elección de ciertos patrones en la literatura cubana contemporánea" - aquéllos que ofrecen mayores posibilidades de escapar "del pabellón de lo inédito" hacia las "praderas de la publicación nacional" - la apertura al flujo editorial transnacional tampoco parece generar en el dominicano la esperanza de que hayan más páginas "redactadas bajo el influjo más genuino de la creación”. Ante la pregunta “¿Cómo visualizas el futuro de la literatura cubana?" Juan Luis Guerra contesta: 


\begin{abstract}
No quisiera sonar pedante, pero lo que uno tiene en mente al pensar en el futuro de la literatura cubana es lo más parecido a este presente subterráneo. Ahora es posible escribir, escriban. Ahora no tienen que agradar a nadie en un sentido comercial. A Cuba van a llegar los grandes grupos editoriales. Va a existir otro tipo de correctores, surgirá una crítica motivada por la rabia y otra por el pago de sus columnas, aparecerán suplementos culturales, revistas literarias con publicidad no literaria. Se formará un tipo de autor no intelectual. El compromiso político será una opción personal. Terminará por definirse lo que hoy es solo un esbozo: el autor celebridad [...] Abrirán sus puertas nuevas librerías y ofrecerán suplementos y páginas web detestables donde se promocionará el libro del mes y siempre será una basura. Habrá listas de los mejores libros del año cuando llegue diciembre, y estarán relacionadas a las editoriales y a sus estrategias de mercado. Pero también aparecerán las listas de los que no tienen nada que perder y expondrán títulos ambiciosos y difíciles de encontrar, porque también aflorarán editoriales independientes que no tardarán en posicionarse entre las de Hispanoamérica, al lado de Beatriz Viterbo, Estruendomudo y Almadía o Alpha Decay, Candaya y Periférica. Y de la confrontación entre los nuevos autores excluidos y los recién llegados grupos editoriales surgirán pequeños cercos de resistencia, a los cuales les costará mucho ver más allá de sus ilusiones colectivas, recicladas y presumiblemente arriesgadas [...]

Habrá booktrailers. Se adaptarán al cine. Y entonces la literatura cubana se parecerá mucho a la literatura internacional y será en definitiva un basurero contemporáneo. (Morales, 2011, p.52)
\end{abstract}

En definitiva, el cuento describe un presente problemático para los autores cubanos: si es cierto que éstos escriben bajo las regulaciones y condiciones de publicación propias de una territorialidad aislada — lo cual sin dudas afecta la calidad literaria de sus textos - la extraterritorialidad, el mundo exterior a la isla que reporta el tío Matt, no parece que fuera a liberarlos de constricciones puesto que allí regirían otras. En este sentido, creo que la cuestión que plantea el cuento no es tanto la de constatar de qué manera la territorialidad en tanto condición de producción — que en el caso de Cuba implica presiones ideológicas, acceso a libros, posibilidades de publicación, gestión estatal de la edición, etc.- deja su huella inevitable y reconocible en una literatura cualquiera, sino más bien qué clase de literatura logra efectivamente escribirse aún en esas -o en cualesquiera otra- condiciones. Un planteo político, creo, en tanto pone el énfasis en lo que puede la literatura: "Ahora pueden escribir, escriban”, advierte Juan Luis Guerra. Dicho de otro modo, toda escritura lleva las marcas de sus condiciones, el asunto es qué puede hacer el escritor a partir de ellas. Algunos, convencidos de que la literatura es un discurso social que, como cualquier otro discurso social, "está anclado" o remite más o menos directamente a la realidad y sus condiciones —incluidas las condiciones para publicar en un país como Cuba - entenderán que la escritura no puede dejar de ser un trabajo sociográfico, un registro más o menos directo de un modo comunitario de pensar, de ser, de estar. O de padecer, cuando los habituales lugares comunes del imaginario (tropical, erótico, heroico) acerca de Cuba son abandonados por el tópico de la escasez, la pobreza, la marginalidad, etc.

Otros, y creo que este es el caso de Morales, entienden que la literatura no tiene con la realidad una relación de registro o testimonio sino, por el contrario, de suspensión o disolución de un orden del mundo que es también un orden del discurso, con sus reglas de visibilidad y enunciabilidad; y, como ocurría en Papyrus, la corrosión de ese orden es propia de una experiencia que se efectúa en el lenguaje mismo. Ese poder de erosión es el poder de la literatura y del escritor, más allá de las condiciones que su territorialidad le imponga. El rechazo a la evaluación de la calidad literaria de un texto en función de su representatividad nacional y, por el contrario, la defensa de la literatura como experiencia de extrañamiento del lenguaje queda planteada de modo contundente en una entrevista realizada a Osdany Morales cuando la periodista, que se muestra sorprendida por que haya "un escritor cubano que ficcionaliza desde una urbe tan cosmopolita como Nueva York", que "rara vez" contemple a La Habana en sus textos, "sin preocuparse de que lo tilden de escapista al alejarse de su contexto” pregunta: “¿Busca OM la extraterritorialidad? ¿Puede un escritor cubano ser extraterritorial?" Morales le contesta: "La extraterritorialidad es una ficción jurídica. Un escritor no es una embajada, ni una base militar. Y menos un deportista olímpico que representa un país. Yo alteraría la pregunta: ¿puede un escritor, de cualquier parte, ser cubano?” (Sánchez, 2016) 


\section{JoRge ENRIQUE LAGE: ESCRIBIR (EN) LA SUPERFICIE}

También los textos de José Enrique Lage son una superficie en la que la escritura habla de la escritura y sus poderes, de unos poderes que se activan cuando se hacen experimentos con el lenguaje. De su formación como bioquímico Lage retiene una regla de oro: "no existen sustancias inocuas, sólo maneras inocuas de utilizar las sustancias" (Grillo, 2012). El carácter letal de una sustancia como el lenguaje depende, por tanto, del montaje de sus elementos, la combinación en dosis calculadas, el sometimiento de los materiales a operaciones diversas: agitación, enfriamiento, saturación. Escribir es un experimento cuyo resultado es una mutación no sólo de la lengua sino del escritor mismo. Escribir convierte a los escritores que pululan en los cuentos y novelas de Lage en otra cosa: pierden su forma humana, transforman radicalmente su aparato perceptivo, modifican su régimen de alimentación. Hay algo de gótico en las ficciones de Lage: el buitre, el vampiro suelen ser las figuras en las que encarna el escritor - es el argumento del cuento "Pensar todo el tiempo en Lorenzo García Vega" -; también el inventor loco, ese que hace injertos y ensambles delirantes — para ejemplo basta el personaje de La autopista que ha reconstruido a Simón Bolívar con partes de distintos cadáveres (Lage, 2016, p.142)—. En Vultureffect(2015), un libro de microcuentos, podrían leerse las características de la poética predatoria que practica Lage: no es el aura de la obra de arte la que habita en la literatura sino otra aura: el buitre, el vulture, cuyo alimento son los desperdicios, los restos, los despojos. El producto de la digestión de esa materia en descomposición es lo que los escritores de los textos de Lage llaman literatura. Y el gran vertedero universal de residuos es, obviamente, la televisión y la web, medios nutricios que abastecen lo que el autor llama la world waste writing de la cual su propia escritura es un exponente.

Aura, también gallinazo: cathartes aura. [...] Se alimentan de carroña, basuras, frutas, reptiles pequeños y televisión. Buscan su alimento con el olfato y no con la vista, como hacen los buitres del resto del mundo, puesto que sus epitelios y sus bulbos olfativos están muy especializados. (Lage, 2015, p.48)

El escritor-buitre encuentra su alimento con el olfato; sus bulbos olfativos lo guían, pero el olor es una percepción que no puede organizarse analíticamente por medio de la lengua, cuyos sistemas de codificación están dirigidos fundamentalmente a las sensaciones visuales y auditivas. El olor es una experiencia inefable: allí naufraga la palabra y su supuesto poder de descripción. Desprovistas de signo, las sensaciones que registra esta escritura vulturizada se suceden sin conexiones lógicas, sin sintaxis alguna, son como unidades fragmentarias que se encajan sin manual de instrucciones previo. De ahí que el punto de partida de muchos de los textos de Lage sea la destrucción de cualquier sistema anteriormente existente que hubiera podido albergar y colocar lo que leemos en un lugar previamente asignado: las historias que cuenta ocurren, por ejemplo, después de la explosión de un planeta o de la destrucción de La Habana por la construcción de una autopista que conecta Key West con la capital de Cuba. En ese paisaje detonado, Lage parece elaborar sus textos a partir de la recolección de materiales desechables, materiales que una cultura echa fuera de sí, montados de un modo cualquiera, sin otro método más que el ensamblaje: “De un tiempo para acá he venido pensando los cuentos como si fueran instalaciones: agregas un elemento, luego otro, amarras por aquí, copias y pegas por allá, vas probando e intercalando materiales [...] y esperas que se cierre algún circuito, que aparezca alguna corriente de sentido. Yo le llamaría "proceso de montaje", dice Lage en una entrevista. (Grillo, 2012).

¿Qué clase de archivo se actualiza en una escritura como ésta? Ninguno que permita reconocer los lugares comunes del archivo literario nacional. Dicho de otro modo: si un archivo es también un lugar no repetiremos aquí las relaciones entre sentido y domicilio/residencia/localización señaladas por Jacques Derrida - los escritores de Lage serían outsiders, seres que han escapado de allí o se han perdido y ni siquiera recuerdan de dónde provienen. Escribir es escribir ese olvido, poner bajo sospecha los recuerdos, huir del sentido al que ellos nos atan. En Carbono 14(2012), por ejemplo, está Frank, un escritor-buitre que, como Evelyn, la protagonista de la misma novela, viene de otro planeta. Evelyn no recuerda nada, sólo una explosión que la lanza al espacio, desnuda y con una Tabla Periódica de Elementos en la mano, que es como "un oráculo 
desfasado o algo por el estilo" (2012, p.145), "muy defectuoso" (p.41). La Tabla responde a las preguntas de Evelyn a través de frases y combinaciones de signos. Evelyn pregunta a la Tabla de dónde viene, y el narrador nos dice que ella "enlazó por su cuenta dos símbolos-sílabas al azar para crear un nombre inverosímil de planeta” (p.42): Cuba, un planeta que ya no existe. Frank, por su parte, está escribiendo un libro que lleva el título de otro libro de Lage: Vultureffect. El objetivo de Frank es que lo que escribe sea irrecuperable para el archivo de su planeta $\mathrm{V}$ : "Tengo que lograr que cuando quieran traducirme a la lengua oficial de $\mathrm{V}$ no sepan cómo hacerlo" (p.132).

Se trata entonces de escribir huyendo de las líneas directrices que el archivo traza para controlar los posibles recorridos por sus materiales: dicho de otro modo, un escritor es el que entiende que con los elementos del archivo jamás podrá armarse un país, de una vez y para siempre. En un cuento previo a Carbono 14, en el que ya aparecen algunos de sus motivos - una niña llamada Evelyn, una Tabla periódica- y que lleva por título "La azotea y la Reina" (2006), el protagonista intenta ayudar a su vecino Douglas C (por Douglas Coupland, pero, nos dice, también por Cuba) en su proyecto delirante: crear una isla con ese nombre. Para eso recurre a una tabla periódica con la que pretende poner orden en el archivo de documentos que ha acumulado el anciano: "Volúmenes de encuadernación casera, periódicos y revistas de nombre desconocido, recortes, folletos, fotografías, cintas de video, mapas. Cuba por acá y Cuba por allá. Cuba por todas partes. El Caos" (2006, p. 228).

La tabla intenta disponer todos esos materiales para que el resultado sea de alguna manera inteligible:

Imaginar, sólo eso. Imaginar un país, una isla (como en las viejas utopías, tiene que ser una isla), con tanta fuerza que los libros y los periódicos y las revistas y los videos y las fotos y los mapas vayan surgiendo poco a poco, caídos por su propio peso, acomodándose como limaduras alrededor de un imán (2006, p. 233).

Finalmente el protagonista, devenido en secretario de Douglas C, construye la tabla con la que intenta organizar los elementos que componen Cuba:

Inertes: héroes $(\mathrm{He})$, neurosis $(\mathrm{Ne})$, artesanía $(\mathrm{Ar})$, crisis $(\mathrm{Kr})$, xenofilia $(\mathrm{Xe})$ y resistencia $(\mathrm{Rn})$. Elemento es, de alguna manera, lo esencial, no necesariamente lo común. Alcalinos: libertad $(\mathrm{Li})$, nación $(\mathrm{Na})$, cultura $(\mathrm{K})$, rabia $(\mathrm{Rb})$, consigna (Cs) y fervor (Fr). Aunque sea lo esencial-mínimo, lo esencial-extraño, lo esencial-terrible" (2006, p. 231).

Sin embargo, al finalizar el proyecto entiende que ese orden (o cualquier otro) es un absurdo: "Con un elemento tras otro no se puede (yo no pude) recrear algo que no existe, al final solo es posible la caricatura, el caos disfrazado de orden [...] darte cuenta cuando ya no tiene remedio (¿por qué estos elementos y no otros?)" (2006, p.232). No hay elementos esenciales sobre las que pueda erigirse una condición ontológica comunitaria. Tampoco hay ningún núcleo identitario bajo la superficie que pueda restituirse, en el improbable caso de que la superficie fuera lo que está arriba de alguna profundidad. Ese es el increíble descubrimiento que realiza JE (Jorge Enrique), el protagonista de Carbono 14, al usar el kit radiométrico comprado en una feria de tecnología para datar con el método del carbono 14 la antigüedad de distintos objetos. Para su sorpresa, descubre que la ropa interior femenina tiene millones de años: es más antigua que cualquier otra cosa que el kit haya testeado. Le revela el secreto a su amigo Frank, el buitre-escritor, quien llega a una conclusión:

-De modo que la ropa interior femenina existe desde antes de que existieran las mujeres — razonó Frank- ¿Crees que las mujeres existen para justificar la existencia de la ropa interior femenina? [...] La ropa interior femenina es una superficie. La última superficie antes del cuerpo $(2012$, p.83)

Sólo que el cuerpo también sería un elemento accesorio, un soporte circunstancial y secundario de aquello que, como la ropa interior, se recambia permanentemente, y en esa permanencia del recambio delata su antigüedad.

Algo similar ocurre en La autopista (2016): en el último capítulo aparece un personaje ciego, con gafas oscuras, de nombre Ray Ban, a cuyo taller mecánico van a parar los autos averiados en la autopista. Pero 
además de mecánico de coches, Ray Ban es el propulsor y único redactor de The Critic, una publicación que busca rescatar las raíces de la cultura cubana sepultadas bajo la autopista:

Ray Ban tenía claro cuál era su papel, cuál era su misión: contra la velocidad y la intemperie, la memoria y el conocimiento. Porque nada estaba perdido aún, aunque todo pareciera irremediablemente perdido. Porque lo que había que reconstruir y salvar era, ni más ni menos, el sustento profundo de la cultura cubana. (2016, p.179)

En los párrafos finales del libro, el guardián de la cultura cubana se ha dormido, y uno de los protagonistas —el Autista - intenta quitarle las gafas. Pero, debajo de esas gafas hay otras, y debajo de esas otras más y así sucesivamente. "Gafas de sol unas sobre otras, tapándose unas a otras. El Autista nunca llegó a verle los ojos a Ray Ban." (2016, p.184).

La autopista termina con este descubrimiento: ningún "sustento profundo", ninguna raíz: tan sólo superficies sobre más superficies.

\section{ESCRIBIR EN/DESDE CUBA: CREAR LA SALIDA}

Escribir como actividad que no remite a ninguna profundidad sino que ocurre a nivel de las superficies; énfasis en el procedimiento antes que en el resultado; atención en el movimiento hacia alguna parte antes que en la llegada o conclusión; relatos que consisten en un escritor que cuenta el libro que escribe o quiere escribir, pero que el lector no llegará a conocer nunca: esta forma de entender la escritura le permite a Lage desentenderse de las demandas de representación identitaria. Como ocurría en Morales, también aquí el "desanclaje" implica un posicionamiento frente a las condiciones de escritura y las políticas que afectan la circulación pública de los textos. Puesto que una de las condiciones para que una escritura rizomática exista - esto es, para que no quede capturada por las instituciones del Estado pero tampoco de la industria editorial- es la de asegurar otra forma de circulación de los signos. Ese posicionamiento queda enunciado de manera contundente en "Miami" (Lage, 2012) un texto que publica tras la muerte de Lorenzo García Vega. Allí Lage rinde homenaje a este autor que cortó las amarras que atan la palabra a la función comunicacional del lenguaje y así, a la deriva, fue a parar a "Playa Albina, la playa del naufragio de la escritura" (2012, p.34), donde los textos se van armando con las "mierditas" y "chucherías" que traen las olas. Desde ese espacio mítico, Lage se pregunta qué puede la escritura:

¿Es posible fundar algo desde ahí, a partir de ahí? Habrá que ver. El crítico Gerardo Muñoz apuntó que ningún escritor cubano de la actualidad estaría dispuesto a cambiar Anagrama por Lorenzo García Vega. Todos quieren ir al supermercado, diría yo, pero nadie quiere ser el bag boy. (2012, p.34)

Escribir en la lengua del bag boy — sostiene Lage - es asumir el riesgo de lo quepuede la literatura cuando el escritor decida apartarse de los caminos que conducen más fácilmente a la publicación segura, la consagración editorial, las regalías. Eso que todavía puede, consiste, creo, en la invención del espacio mismo en el que una enunciación autista pueda ser (des)articulada. En esta clave, propongo, adquieren otro significado los proyectos de agenciamiento colectivo de los que el propio Lage fue miembro en la primera década de los 2000, como el colectivo Espacio Polaroid, la revista 33 y 1/3 (2005-2010) o la revista The revolution evening post (2006-2008). En estas experiencias, el dictum "lo que puede la literatura pese a las condiciones existentes" se transforma en "lo que puede la literatura cuando logra crear otras condiciones para existir". Sospecho que algo de eso es lo que Lage quiere decirnos en "15000 latas de atún y no tenemos cómo abrirlas" (2007), otro relato (más) sobre escritores. En ese cuento, un joven escritor cubano busca infructuosamente una editorial para publicar su primera novela. Todas las editoriales de Cuba le dan la misma respuesta: ya no estamos publicando libros, no tenemos nada que ver con eso. De hecho, ni siquiera traen a Cuba "esos libros de los que todos hablan y que hace cinco, diez, veinte años, pasaron por las manos del resto del mundo". En esa búsqueda, entra en contacto con una extraña editorial que contrabandea cajas llenas de "piezas para armar 
cualquier cosa": algo así como células madre para engendrar ficciones. El escritor se suma a la operación de contrabando que traman los singulares empleados de la editorial, pero la policía los descubre y comienza a perseguirlos. Pero tras varios intentos fallidos (“me salieron [...] un párrafo de Thomas Pynchon, dos rocas marcianas Spirit y una rata de laboratorio”), el escritor logra con esas piezas armar cortinas de humo y un fusil con el que se defiende de sus perseguidores. Finalmente, la policía cerca el vehículo y conmina al escritor y a sus cómplices a entregarse. Éstos le piden que "arme algo", y el escape ocurre a través de un recurso inesperado:

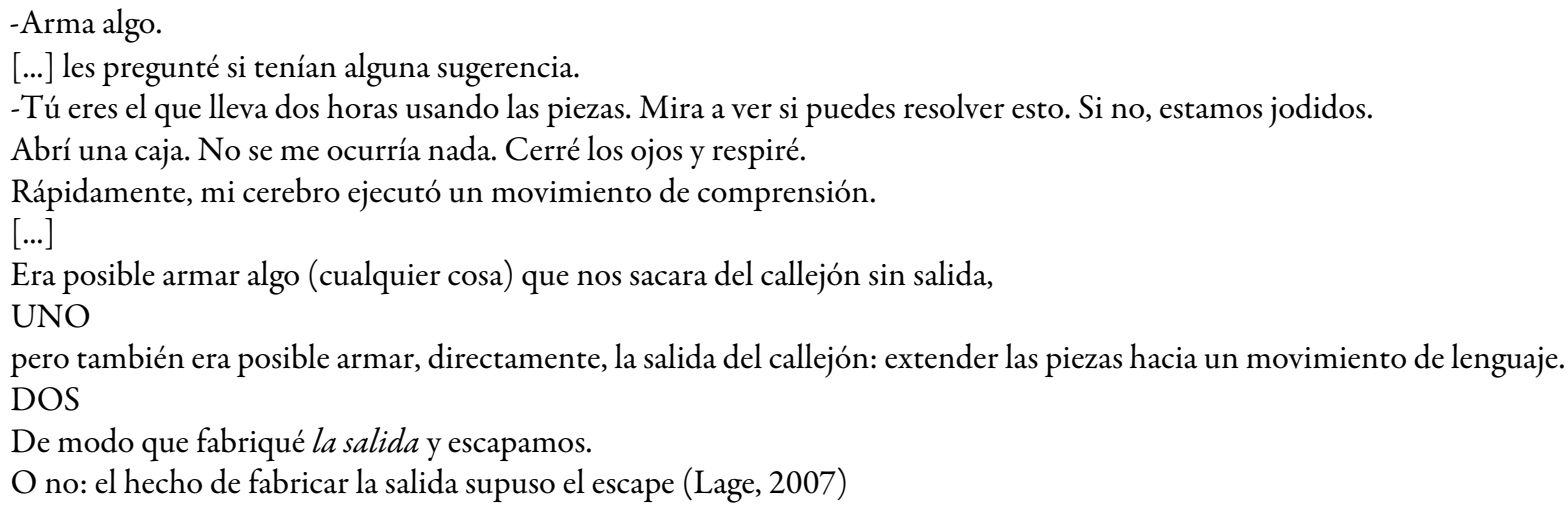

En vez de hallar el medio para salvarse en esa encerrona pero dejando intacto el callejón sin salida, el escritor del cuento crea directamente la salida. Como si hubiera entendido que nunca estarán dadas las condiciones para publicar una literatura hecha de "mierditas" y "chucherías" ensambladas, sino que esas condiciones deben ser creadas. Por eso es que en el texto que abre el primer número de la revista 33 y $1 / 3$, y de la que Lage fue uno de sus editores, se nos dice que ésta es una revista menos:

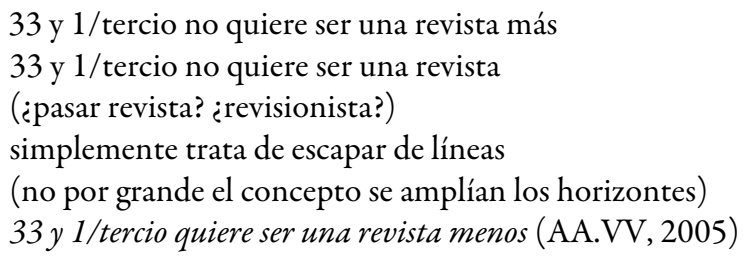

Este espacio de enunciación-otro no pertenece al lugar en el que están todas las otras revistas conocidas, allí donde estas pueden entrar en diálogo o en debate haciendo un sistema más o menos orgánico, sino que se va construyendo mientras sucede la fuga del lugar común de la literatura nacional: es, dijimos, la playa del naufragio. Este locus de enunciación que crea la revista no opone una resistencia antagónica, sino que inventa una forma de escapar a los modos institucionalizados de representación de la función literaria. Es un experimento en el que se reconocen las huellas de Gilles Deleuze (Deleuze y Parnet, 1980, p.45): busca ser al mismo tiempo escape y arma, salida y medio de salida a la vez.

Así, en los textos de Osdany Morales y de Jorge Enrique Lage que he analizado no es la profundidad de los valores ideológicos que se defienden ni la declamación de supuestas verdades lo que habilita su lectura política. Tampoco el testimonio de la ruina ni la denuncia. Su carácter polémico reside no en lo que dicen, sino en cómo funcionan: obstruyen la lengua del orden sin otro recurso más que el de conservarse a flote tras haberse aligerado de cualquier fin o misión que se le hubiera asignado. Siempre a nivel de la superficie de una escritura que no apunta a ningún referente exterior, que no ancla en nada más que en ella misma, ejerciendo desde ese lugar el poder que es propio de la literatura: el de interrumpir las configuraciones simbólicas dominantes, de suspender cualquier certeza sobre lo que el texto afirma, de creación de un (no) lugar en donde esa incertidumbre pueda ser dicha. 


\section{REFERENCIAS}

AA.VV. (2005). Play, Revista 33 y 1/3. Recuperado de http://revista33yl tercio.blogspot.com/p/numeros.html

Aguilera, C. A. (2020). Teoría de la transficción. Hypermedia. Recuperado de https://www.hypermediamagazine.co $\mathrm{m} /$ literatura/novedades/teoria-de-la-transficcion/

Casamayor Cisneros, O. (2013). Utopía, distopía e ingravidez: reconfiguraciones cosmológicas en la narrativa postsoviética cubana. Madrid: Iberoamericana; Frankfurt am Main: Vervuert Verlag.

Deleuze, G. y Parnet, C. (1980). Diálogos. Valencia: Editorial Pre-Textos.

Dorta, W. (2017). Narrativas de la Generación Cero: escenas de traduccio\#n, cosmopolitismo y extran\#amiento. Revista de estudios hispánicos, 51, 349-367.

Grillo, R. (2012). La toxicidad de la ficción, una idea que me persigue... Entrevista a Jorge Enrique Lage. Recuperado de https://www.isliada.org/la-toxicidad-de-la-ficcion-una-idea-que-me-persigue/

Grillo, R. y Luis, L. (2008). Año 0. Los benditos se reúnen. Recuperado de http://www.kaosenlared.net/noticia/ano -o-los-benditos-se-reunen

Lage, J. E. (2012). Carbono 14: (una novela de culto). La Habana: Editorial Letras Cubanas.

Lage, J. E. (2016). La autopista: The movie. Nueva York: Sudaquia.

Lage, J. E. (2012). Miami, Revista Voces, 17, 33-35.

Lage, J. E. (2015). Vultureffect. Leiden: Bokeh.

Lage, J. E. (2006). “La azotea y la Reina”. Confluencia, 22 (1), 227-233.

Lage, J. E. (2011 [2007]). 15.000 latas de atún y no tenemos cómo abrirlas. Recuperado de https://www.isliada.org/ 15-000-latas-de-atun-y-no-tenemos-como-abrirlas/

Lage, J. E. (2018 [2007]). Pensar todo el tiempo en Lorenzo García Vega. Recuperado de https://www.isliada.org/p ensar-todo-el-tiempo-en-lorenzo-garcia-vega/

Mora, J. y Pérez, A. (2017). Long Playing Poetry. Cuba: Generación Años Cero. Richmond, USA: Casa Vacía.

Morales, O. (2012). Papyrus. Nueva York: Sudaquia.

Morales, O. (2011) Querido sobrino Gobo. Revista Quimera, 331, $49-53$.

Morales, O. (2014). Las playas albinas. México: Librosampleados.

Navia, MJ. (2013). El delirio de contar historias. Recuperado de https://ticketdecambio.wordpress.com/2013/01/29 /el-delirio-de-contar-historias/

Padilla Cárdenas, G. (2014). El factor Cuba. Apuntes para una semiología clínica, Temas, 80, 114-120.

Puñales Alpízar, D. (2018). La cómoda disidencia: estrategias de escritura y publicación en la Cuba actual. En E. Gallardo-Saborido, J. Gómez-de-Tejada, D. Puñales-Alpízar (eds.) Asedios al caimán letrado: literatura y poder en la Revolución Cubana (pp.113-128). Praga: Universidad Carolina.

Rojas, R. (2018). La generación flotante: apuntes sobre la nueva literatura cubana. Recuperado de https://www.revistadelauniversidad.mx/articles/e51b17ed-9e3d-430f-981c-90bc3974d061/la-generacion-f lotante-apuntes-sobre-la-nueva-literatura-cubana.

Sánchez, L. (2016). Osdany Morales. A propósito de la extraterritorialidad como ficción jurídica. Recuperado de http://www.centronelio.cult.cu/noticia/osdany-morales-prop\%C3\%B3sito-de-la-extraterritorialidad-como -ficci\%C3\%B3n-jur\%C3\%ADdica

Villasana, O. (2013). Reseña a Papyrus de Osdany Morales. Revista Nagari, 3. Recuperado de https://issuu.com/nag arimagazine/docs/nagari_3_cecin_estpasmexique 